\title{
Ditadura civil-militar e a aparência de normalidade constitucional: análise dos discursos na instalação do Conselho de Defesa dos Direitos da Pessoa Humana
}

\author{
Civic-military dictatorship and the appearance of constitutional \\ normality: discourse analysis on the installment of the Human \\ Person Rights Defense Council
}

Leonardo Fetter da Silva ${ }^{1}$

\begin{abstract}
Resumo: a instalação do Conselho de Defesa de Direitos da Pessoa Humana (CDDPH) ocorreu no ano de 1968, pelo ditador-presidente Costa e Silva, e tinha como objetivo abrir um espaço de diálogo e apuração de violações de Direitos Humanos. Esse espaço institucional estava sendo solicitado pela oposição e por uma parcela da sociedade como lugar legítimo para denunciar os crimes cometidos pelo aparato repressivo institucional da ditadura civil-militar. Na cerimônia de instalação do Conselho, o presidente e o Ministro da Justiça Gama e Silva proferiram discursos sobre a defesa dos Direitos do Humanos e a caraterização, através da abertura do CDDPH, do regime enquanto democrático, constitucional e em consonância com o Estado de direito. Isso posto, o presente artigo busca destacar os conceitos por trás desses elementos e demonstrar como eles foram acionados ao legitimar como democrática uma ordem autoritária. Dessa forma, destacando o aspecto marcante da ditadura brasileira de manter, aparentemente, uma normalização institucional e constitucional.
\end{abstract}

Palavras-chave: Ditadura civil-militar. Direitos humanos. Estado de direito.

\begin{abstract}
Defense Council of Human Person Rights (CDDPH) installment occurred in 1968, by the president Costa e Silva, and it had as an objective to open up a space of dialogue and verification of Human Rights violations. This institutional space was requested by the opposition and a portion of society as a legitimate place for denouncing the crimes perpetuated by the institutional repressive apparatus of the civic-military dictatorship. In the Council installment ceremony, the president and the minister of justice, Gama e Silva, made speeches regarding Human Rights defense and the characterization, through the CDDPH opening, of the regime as democratic, constitutional and in accord with the rule of law. For this reason, the present essay seeks to outline the concepts behind these elements and to demonstrate how they were engaged to legitimate as democratic, an authoritarian order. In this way, highlighting the significant aspect of the Brazilian dictatorship of maintaining, apparently, an institutional and constitutional normalization.
\end{abstract}

Keywords: Civic-military dictatorship. Human rights. The rule of law.

${ }^{1}$ Pontifícia Universidade Católica do Rio Grande do Sul, Porto Alegre, RS, Brasil. .Mestre em História no Programa de Pós-graduação em História da Pontifícia Universidade Católica do Rio Grande do Sul (PUCRS), Porto Alegre, RS, Brasil. Licenciado em História pela mesma instituição.ORCID: http://orcid.org/0000-0003-4531-8736.E-mail: leonardofetter.LF@gmail.com 


\section{Introdução}

Por meio de uma cerimônia oficial, em outubro de 1968, o ditador-presidente Costa e Silva instalou o Conselho de Defesa dos Direitos da Pessoa Humana (CDDPH) - um dispositivo criado em lei pela sanção do presidente João Goulart poucos dias antes do golpe civil-militar de 1964. Tal instrumento tinha como objetivos defender os Direitos Humanos no Brasil, além de realizar inquéritos e investigações de denúncias que chegavam até ele e, assim, promover um efetivo gozo de tais garantias por todos os brasileiros. Entretanto, o CDDPH foi aberto por um regime que estava sendo constantemente acusado de promover crimes aos Direitos Humanos, com um aparato repressivo e de censura cada vez mais forte ${ }^{2}$. Além disso, passados dois meses, esse mesmo governo lançou o Ato Institucional número 5 (AI-5), que, entre todas as medidas, promoveu o cerceamento dos direitos e garantias constitucionais, assim, mostrando que a política de Direitos Humanos não era de fato um objetivo de Costa e Silva ou do regime.

A partir disso, o presente artigo busca analisar os discursos de Costa e Silva e do então Ministro da Justiça Luis Antônio da Gama e Silva na cerimônia de instalação do Conselho de Defesa dos Direitos da Pessoa Humana, no Rio de Janeiro, em 24 de outubro de 1968. Com isso, destacando, por meio da análise discursiva, a apropriação do discurso liberal de defesa do Estado de direito, liberdade, democracia e direitos do homem como forma de legitimação do governo, encarado dentro de uma lógica autoritária. Tais discursos foram publicados, na íntegra, na edição do Correio da Manhã de 25 de outubro de 1968, com a matéria intitulada "Direitos: Conselho Instalado" (DIREITOS..., 1968, p. 2). Dessa forma, pretende-se realizar a discussão em torno dos direitos fundamentais, Estado de Direito e relação do Estado liberal - dentro de uma definição da doutrina liberal -, como forma de pensar a análise desses discursos.

\section{Ditadura civil-militar e o CDDPH}

Com a construção dos Direitos Humanos, proclamado na declaração em 10 de dezembro de 1948, iniciou-se um amplo processo de institucionalização desses direitos em vários países pelo mundo - apoiado em convenções e acordos internacionais. O Brasil fez parte desse processo internacional ao votar e aprovar tanto a Declaração Universal dos Direitos Humanos, adotada pela Organização das Nações Unidas (ONU), quanto a Declaração Americana dos Direitos e Deveres do Homem, ambas de 1948. Internamente no país, por meio do Deputado Federal Bilac Pinto (UDN), de maneira pioneira criou-se o Conselho de Defesa dos Direitos da Pessoa Humana através do Projeto de Lei 1221/56, apresentado em 25 de abril de 1956. Tal projeto buscou a criação de um órgão nacional, ligado ao Ministério da Justiça, que fosse capaz de promover investigações e estudos acerca dos crimes aos Direitos Humanos, bem como a punição e medidas capazes de afirmar tais garantias. Além disso, o projeto definiu como função do Conselho:

\footnotetext{
2 Essa mesma estranheza em torno da instalação e manutenção do CDDPH durante todo o período da ditadura civil-militar, com interrupção do governo Geisel de 1974 até 1979, que guia a minha dissertação em andamento intitulada "A ditadura civil-militar e os Direitos Humanos: o Conselho de Defesa dos Direitos da Pessoa Humana (1964-1985)" - pesquisa que possui apoio do CNPq.
} 
Art. $4^{\circ}$ Compete ao Conselho de Defesa dos Direitos da Pessoa Humana: $1^{\circ}$ promover inquéritos, investigações e estudos acerca da eficácia das normas asseguradoras dos direitos da pessoa humana, inscritos na Constituição Federal, na Declaração Americana dos Direitos e Deveres Fundamentais do Homem (1948) e na Declaração Universal dos Direitos Humanos (1948); [... $3^{\circ}$ promover nas áreas que apresentem maiores índices de violação dos direitos humanos: a) a realização de inquéritos para investigar as suas causas e sugerir medidas tendentes a assegurar a plenitude do gozo daqueles direitos; b) campanha de esclarecimento e divulgação; [...] 13. receber representações que contenham denúncias de violações dos direitos da pessoa humana, apurar sua procedência e tomar providências capazes de fazer cessar os abusos dos particulares ou das autoridades por eles responsáveis. (BRASIL, 1956)

Após oito anos de tramitação, o projeto foi transformado na Lei no . 4319/64 pelo sancionamento do então presidente João Goulart, em 16 de março de 1964 (BRASIL, 1964). Porém, passados poucos dias, ocorreu um golpe articulado entre civis e militares que destituiu o presidente e instaurou uma ditadura civil-militar ${ }^{3}$ no país, deixando em segundo plano a instalação e o efetivo funcionamento do Conselho.

O movimento que protagonizou o golpe civil-militar deflagrado em 31 de março de 1964 se intitulava de "Revolução" e tinha como objetivo extirpar o comunismo da sociedade brasileira e salvar a democracia: "O golpe foi dado em nome da democracia, supostamente ameaçada. O regime instaurado jamais se assumiu como ditadura, no máximo como "democracia relativa”. Sempre se preocupou em manter uma fachada democrática” (RIDENTI, 2014, p. 30). O primeiro momento pós-golpe foi o de reprimir as manifestações contrárias ao movimento e o seu poder ficou em torno da Junta Militar, que reunia os chefes das três armas (exército, aeronáutica e marinha). No dia 9 de abril, a Junta expediu o primeiro Ato Institucional - instrumento que foi recorrentemente usado no regime para dar tom de legalidade ao domínio militar -, assim, decretando um Estado de exceção no país. A partir desse Ato, a Junta "começou a decretar cassação de mandatos eletivos, a suspensão de direitos políticos, por dez anos, além da aposentaria de civis e reformas de militares, atingindo centena de pessoas" (REIS, 2000, p. 35). Portanto, limpou-se o terreno com cassações de diversos deputados federais e se

\footnotetext{
3 Aqui ressalto o leque historiográfico iniciado, essencialmente, com o historiador Daniel Aarão Reis no livro "Ditadura Militar, esquerdas e sociedades" de 2000, que propõe destacar as relações do regime instalado em 1964 com a sociedade, suas colaborações e a inserção de civis no seu interior. Dessa forma, ao analisar o Conselho de Defesa dos Direitos da Pessoa Humana que possuía, dentro de seus integrantes, membros civis e entidades civis, portanto, inseridos no interior da ditadura, acho proveitoso destacar a nomenclatura da ditadura como civil-militar - além de todo debate historiográfico nessa inserção civil no interior desse e de outros regimes autoritários. Entretanto, não há um consenso dos historiadores sobre essa nomenclatura, por exemplo: Carlos Fico (2016) e Marcos Napolitano (2017) por mais que concordem que o regime teve uma participação civil ativa, entendem que as decisões e os maiores postos da administração do Estado foram ocupados por militares, por isso suas defesas no termo ditadura militar. Por outro lado, o golpe de 31 de março de 1964 tem um maior consenso nos debates historiográficos como civil-militar, ou seja, a efetiva colaboração de militares e civis no processo de golpe e sua sucedida instalação.
} 
elegeu indiretamente o marechal Castelo Branco como presidente pelo Congresso Nacional, transformado em Colégio Eleitoral. ${ }^{4}$

Coube a Castelo Branco refirmar a ordem e os objetivos do movimento golpista e, assim, se transformar no verdadeiro construtor institucional do regime autoritário ${ }^{5}$. No governo dele

foram editados quatro Atos Institucionais, a Lei de Imprensa e a Nova Constituição, que selava o princípio de segurança nacional e que, doravante, deveria nortear a vida brasileira. [...] Na dinâmica das sanções legais aos adversários do regime com base nos Atos Institucionais, o governo Castelo Branco se destaca: dos 5.517 punidos por este tipo de ato no regime, 65\% (ou 3.644) o foram durante o governo Castelo. Além de civis, os militares afinados com o governo deposto foram particularmente punidos durante o governo de Castelo, concentrando cerca de $90 \%$ das 1.230 sanções feitas a militares ao longo do regime. (NAPOLITANO, 2017, p. 73)

Além disso, foi no final do governo de Castelo que se instituiu a Lei de Segurança Nacional, que substituía a Lei de 1953, baseada na Doutrina de Segurança Nacional (DSN) ${ }^{6}$. Ela estabelecia que todo brasileiro fosse responsável pela Segurança Nacional (SN), ou seja, qualquer pessoa que tivesse uma informação que fosse contra essa segurança e não levasse às autoridades era considerada criminosa, criando-se, assim, a "cultura do medo" e terror. Assim como as demais ditaduras instaladas a partir da segunda metade do século XX na América Latina, mais especialmente na América do Sul, a brasileira se inspirou na DSN e buscou extirpar o comunismo da sociedade brasileira, bem como "garantir" a democracia e a Segurança Nacional. Essa doutrina estava baseada na guerra contra um "inimigo interno" que "implicou numa 'guerra interna', permanente, ‘total' e, consequentemente, ‘suja' - ou seja ilegal e clandestina. A necessidade de implementar as diretrizes da SN exigiu o confronto total com a oposição, numa

\footnotetext{
4 Muito daqueles que apoiaram o movimento golpista que destituiu o João Goulart e nos dias seguintes elegeram Castelo Branco como presidente acreditavam que seu governo era provisório, que iria reestruturar a democracia brasileira e encaminhá-la para as eleições presidenciais previstas para o ano seguinte, o que de fato não ocorreu. Isso demonstra a mudança brusca, nos meses seguintes ou no outro ano, dos apoiadores para opositores da ditadura civil-militar, denunciando suas exceções e arbitrariedades - nesse grupo se encaixam setores civis, políticos e também parte da imprensa.

5 O historiador Marcos Napolitano trabalha com dois mitos que surgem sobre o esse período da ditadura civil-militar: primeiro, a ideia de uma "dita branda" no período do golpe até o AI-5, em 1968, onde os defensores dessa tese "afirmam que nos primeiros quatro anos do regime ainda existia o recurso de habeas corpus, mobilizado pela defesa de muito presos durante o golpe, bem como certa liberdade de imprensa, de expressão e de manifestação" (NAPOLITANO, 2017, p. 70). Segundo o autor, com o AI-5 a tortura, os desaparecimentos de presos políticos, a censura prévia e o cerceamento do debate político-cultural atingiram seu ponto máximo, mas isso não significa que anteriormente não ocorreu nenhuma atividade arbitrária do Estado - "obviamente não faltam momentos de conflito entre o regime e os setores de oposição antes do AI-5, que muitas vezes redundaram prisões, inquéritos policial-militares e atos censórios de obras artísticas" (NAPOLITANO, 2017, p. 72). A partir disso, o segundo mito se estrutura, onde surge na década de 70 uma memória "castelista" de um projeto inicial de Castelo, com verdadeiras intenções democráticas, que havia sido abandonado pela chamada "linha dura" dos militares - ou seja, um ditador bem-intencionado que sucumbiu às pressões da extrema direita-militar. Segundo Napolitano, essa memória surge essencialmente na imprensa liberal, "a mesma imprensa que entre 1966 e 1967, considerava Castelo um ditador e depositava as esperanças de liberalização em Costa e Silva” (NAPOLITANO, 2015, p. 21).

6 A Doutrina de Segurança Nacional (DSN) foi elaborada por militares norte-americanos nas décadas de 50 e 60, no contexto da Guerra Fria, na National War College. O objetivo era a contenção do comunismo e ganhou destaque na aplicação na América Latina, onde oficiais militares foram até os EUA aprender técnicas e serem preparados. Além disso, ganhou bastante força com a incorporação de teorias francesas, como a Guerra de Contra Insurgência, aplicadas nas guerras e conflitos coloniais. A doutrina foi incorporada e adaptada no Brasil para a sua realidade, encontrando bastante adesão devido ao anticomunismo presente nas elites militares (MENDES, 2014).
} 
luta sem compromissos nem negociações e que só poderia terminar com a destruição total e permanente do adversário" (PADRÓS, 2007, p. 48). Além disso, acabaram estendendo esse preceito para todos aqueles que não iam de acordo com a ordem autoritária que se instalava. Acompanhada a essa doutrina, estabeleceu-se no regime a prática de Terrorismo de Estado ${ }^{7}$ com a estruturação e institucionalização da repressão durante a ditadura civil-militar.

Esses regimes caracterizam-se em sua forma repressiva pela imposição do medo e do terror, que configuram uma "cultura do medo", originária das práticas repressivas e da lógica de suspeição. No exercício da coerção física e psicológica, utilizaram-se, de forma institucional e racionalizada, de práticas como o sequestro, como forma de detenção; a tortura física e psicológica, como dominadoras do medo; e a morte e a desaparição, como políticas de extermínio. Além disso, a atuação do aparato repressivo de tais regimes não ficou circunscrita às fronteiras políticas de cada país, evidenciando a colaboração e cooperação desse aparato no combate do "inimigo interno", estipulado pela "fronteira ideológica" (BAUER, 2006, p. 16).

O momento mais efetivo da política de terror de Estado e a Doutrina de Segurança Nacional no Brasil foi após a promulgação do Ato Institucional n. ${ }^{\circ} 5$ (AI-5), em 13 de dezembro de 1968.

O final do governo Castelo Branco ficou marcado pelo descrédito e pela insatisfação: no campo político, havia perdido credibilidade com os deputados da base no Congresso Nacional, além do descontentamento de uma ala dos militares; e do ponto de vista da sociedade, a repressão e a recessão, que não havia ainda sido superada, deram um ar de fracasso, principalmente nos centros urbanos. Coube ao governo de Arthur Costa e Silva trabalhar as questões econômicas e sociais a partir de 1967, após ser eleito no ano anterior indiretamente pelo Congresso Nacional.

Na gestão de Costa e Silva, o ano de 1968 ficou marcado pela onda de protestos que se iniciou por todo o Brasil, com destaque aos estudantes, de crítica à ditadura civil-militar. Em contrapartida, os atos foram fortemente repreendidos pelas polícias ${ }^{8}$. Segundo o historiador Carlos Fico

Esse foi um ano marcante na história recente no Brasil, sendo surpreendente a série de eventos chocantes que aconteceu: assassinatos de estudantes pela repressão, assassinatos de militares estrangeiros pela esquerda, prisão do ex-presidente da República Jânio Quadros, ataques a espetáculos teatrais com sequestro e espancamento de artistas, entre outros (FICO, 2016, p. 63).

\footnotetext{
7 Cf. PADRÓS, Enrique Serra. Como el Uruguay no hay...: terror de Estado e segurança nacional Uruguai (1968-1985): do pachecato à ditadura civil-militar. 2005. Tese (Doutorado em História) - Universidade Fedreal do Rio Grande do Sul, Porto Alegre, 2005.

8 A insatisfação geral da sociedade frente à ditadura civil-militar, inclusive da ala que havia apoiado o golpe, e de outro lado, a radicalização de organizações revolucionárias para a luta armada, serviram de pretexto dos militares para a promulgação do Ato Institucional n. ${ }^{\circ} 5$ - "As organizações revolucionárias clandestinas, que controlavam quase todas as entidades representativas, apareciam nas manifestações com propósitos que ultrapassavam o escopo próprio do movimento, e gritavam palavras de ordem de enfretamento, inclusive armado" (REIS, 2000, p. 49). Esse Ato representou um fechamento do regime, considerado por alguns historiadores um "golpe dentro do golpe", e fechou "todos os parlamentos por tempo indeterminado, recobrando amplos poderes discriminatórios e reinstaurando, de modo inaudito, o terror da ditadura" (REIS, 2000, p. 51). Além disso, deu ao presidente, ditador, plenos poderes sobre o legislativo e outras esferas institucionais, a partir desse momento as garantias jurídicas não ficaram devidamente asseguradas.
} 
No dia 28 de março, o estudante Edson Luis foi morto por policiais, no restaurante Calabouço, Rio de Janeiro, em uma repressão a uma manifestação estudantil, e milhares de pessoas acompanharam o seu enterro. O fato circulou nos jornais e teve grande repercussão nacional, já que a censura rigorosa sobre a imprensa não havia sido implantada. Durante o ano, várias universidades foram invadidas pelas forças policiais com o intuito de reprimir as manifestações estudantis: no mês de agosto, a Universidade de Brasília; em setembro foi à Universidade de Minas Gerais; e em outubro à Universidade de São Paulo. No Rio de Janeiro, ocorreu no dia 26 de junho a chamada Passeata dos Cem Mil, que marcou a insatisfação sobre as prisões e arbitrariedades da ditadura civil-militar, sendo que o Ministro da Justiça, Gama e Silva, havia proibido as manifestações e os comícios, o que se mostrou inútil. Nesse mesmo ano, os trabalhadores metalúrgicos das cidades de Contagem (MG) e Osasco (SP) realizaram greves nos meses de abril e julho, cabendo destacar que as manifestações de trabalhadores haviam sido amplamente repreendidas nos primeiros anos da ditadura. Além disso, em 12 de outubro inúmeros estudantes foram presos no congresso da clandestina União Nacional dos Estudantes, em Ibiúna, interior paulista.

Nesse contexto de insatisfação, de denúncias de violências repressivas e de crimes aos Direitos Humanos, o Conselho de Defesa dos Direitos da Pessoa Humana (CDDPH) volta para o debate na Câmara de Deputados, pelos congressistas da oposição, como um espaço institucional e legítimo para essas denúncias serem realizadas. Entidades como a Ordem dos Advogados do Brasil (OAB) e a Associação Brasileira de Imprensa (ABI), que eram definidas em lei como membros do Conselho, também cobravam sua instalação para fins de apuração a essas violações aos Direitos Humanos. Dessa forma, no dia 24 de outubro o então presidente Costa e Silva instalou o Conselho em uma cerimônia realizada no Palácio das Laranjeiras, no Rio de Janeiro. Sua instalação não promoveu um amplo debate de garantia e defesa dos Direitos Humanos e só foi realizada para atender uma demanda de parte da sociedade por um mínimo de espaço para denunciar esses crimes, como já apresentei no artigo "A ditadura civil-militar e os Direitos Humanos: o Conselho de Defesa dos Direitos da Pessoa Humana” (SILVA, 2017, p. 8).

Cabe ponderar que o CDDPH se manteve instalado em todos os governos militares, salvo o governo de Geisel (1974-1979). Durante esse período, o Conselho não teve regularidade de reuniões e esteve sempre à mercê das intenções do Ministro da Justiça em atuação. Além disso, todas as denúncias de tortura, desaparecimento e morte de presos políticos que chegaram até o órgão foram arquivadas tendo como base os documentos e declarações oficiais produzidos pelos órgãos de repressão. Algumas questões, como os esquadrões da morte e sobre a situação indígena, tiveram mais espaço de discussão, mas não obtiveram resultados efetivos na defesa dos Direitos Humanos ${ }^{9}$. Sobretudo, durante toda a ditadura civil-militar, o CDDPH esteve sempre controlado pelos militares e na primeira tentativa de uma efetiva investigação (que foi frustrada), no caso de desaparecimento do ex-deputado Rubens Paiva ${ }^{10}$,

\footnotetext{
9 As discussões do CDDPH ficaram basicamente envolvidas em torno dos torturados, presos, mortos e desaparecidos políticos, sendo poucas abordagens de questões mais ampliadas dos Direitos Humanos.

10 Até o momento de apreciação da denúncia de desaparecimento pelas forças repressivas do ex-deputado e engenheiro Rubens Paiva, todos os casos de presos políticos que chegaram ao CDDPH foram arquivados imediatamente. A votação de procedimento ou arquiva-
} 
o governo atuou para cercar ainda mais o órgão e resultou na Lei 5.763/1971 (BRASIL, 1971). Essa lei foi proposta pelo senador governista Rui Santos e fez modificações que garantiram o controle do governo sobre o Conselho: tornou as reuniões sigilosas e aumentou o número de membros, incorporando cadeiras ligadas ao governo ${ }^{11}$.

\section{Discursos na cerimônia de instalação do CDDPH}

Como já mencionado, a instalação do Conselho de Defesa dos Direitos da Pessoa Humana ocorreu em outubro de 1968, com a presença de diversas autoridades, incluindo um representante da ONU. Nessa cerimônia discursaram o então presidente Arthur Costa e Silva e o Ministro da Justiça Luis Antônio da Gama e Silva (DIREITOS..., 1968, p. 2) - jurista e professor catedrático de Direito que já havia ocupado o cargo de reitor da Universidade de São Paulo (USP), 1963-1966, e de Ministro da Educação e Cultura (1964), bem como possuía uma vida política ativa ${ }^{12}$. Gama e Silva, como era conhecido, apoiou o golpe civil-militar de 1964 e se articulou com o movimento golpista, assim como demais juristas naquele contexto e posteriormente no período ditatorial.

No discurso do então presidente Costa e Silva podem ser destacados cinco pontos nos quais se concentrou toda sua fala: em primeiro lugar, as partes formais da cerimônia de instalação do Conselho de Defesa dos Direitos da Pessoa Humana, onde se dirige aos conselheiros presentes na cerimônia como "nobilíssima e ingente tarefa a realizar" e desejando a eles um "um trabalho orgânico, equilibrado, racional", bem como o respeito à Constituição e aos demais acordos internacionais de garantia do Direito do Homem. O segundo ponto destacado também tem um caráter formal, mas diz respeito aos tratados internacionais que o Brasil estava participando e à institucionalização dos Direitos Humanos, assim, lançando o marco histórico com a criação da "Declaração do Homem" pela Assembleia das Nações Unidas, em 10 de dezembro de 1948. Além disso, também ressalta a IX Conferência Internacional Americana, realizada em Bogotá, que aprovou a Declaração e Deveres do Homem, segundo o então presidente como um “documento de relevante importância histórica e moral, tornando-se uma autêntica ata cívica dos cidadãos do novo mundo" (DIREITOS..., 1968, p. 2). Dessa forma, seriam os ideários das

mento da denúncia de Paiva acabou empatada na reunião do dia 17 de julho de 1971, ou seja, pela primeira vez se teve uma possibilidade concreta de investigação. Porém, dias após, o Ministro da Justiça Alfredo Buzaid utilizou o seu direito de voto minerva e desempatou a votação, enviando a denúncia para arquivamento.

${ }_{11}$ O Projeto de Lei foi duramente criticado pela ABI, OAB e MDB, que denunciavam o cerceamento da liberdade do CDDPH. Após aprovado, resultou na retirada da OAB e do MDB temporariamente do órgão, como forma de protestos a essas mudanças impostas pelo governo e a desvirtuação dos objetivos inicias do Conselho.

12 Durante ditadura do Estado Novo, Gama e Silva foi demitido do cargo que ocupava como redator-chefe do Correio Paulista, por sua incompatibilidade com o regime. Após a queda de Getúlio Vargas, retornou ao posto dentro do jornal em 1945. Entre esse período, em 1944, foi nomeado por concurso como livre-docente de direito internacional privado na Faculdade de Direito da USP. Em 1953, ele foi nomeado professor catedrático na mesma instituição, como também se tornou professor da Pontifícia Universidade Católica de Campinas. Gama e Silva articulou-se com o movimento que promoveu o golpe civil-militar de 1964 e apoiou o novo regime instalado. Desse momento até a posse do general Castelo Branco, o jurista assumiu o Ministério da Educação e Cultura no curto tempo do provisório governo presidencial do Deputado Pascoal Ranieri Mazzilli (01/04/64-15/04/64). No mesmo ano, o ditador-presidente Castelo Branco lhe ofereceu o cargo de procurador-geral da república, que foi recusado por assumir cargo de juiz da Corte Internacional de Haia, Holanda. Após dois anos, assumiu o cargo de reitor da Universidade de São Paulo em 1966. Afastou-se do cargo no início do ano seguinte para assumir o Ministério da Justiça no governo de Costa e Silva, ficando até 30 de outubro de 1969, final da Junta Provisória e início do governo Médici - Verbete Luis Antônio da Gama e Silva (BELOCH; LATTMAN-WELTMAN; LAMARÃO, 2001). 
Assembleias Internacionais que inspiraram a Lei 4.319/64 que, portanto, aprovou a criação do Conselho. O terceiro momento seria a constante busca da relação dos pressupostos dos "Direitos do Homem" com a "sabedoria bíblica", destacando os ensinamentos do Papa João XXIII na defesa da "sagrada dignidade da pessoa humana".

Adiante, o quarto ponto trata da ideia de os "Direitos do Homem" como um processo evolutivo da humanidade, um caminho para o progresso, marcado por grandes acontecimentos históricos “como na Revolução Inglesa de 1668, na Declaração da Independência dos Estados Unidos, nos princípios filosóficos da Revolução Francesa, nas liberdades fundamentais de Roosevelt" (DIREITOS..., 1968, p. 2). Dentro desse raciocínio a "revolução democrática brasileira”, definida por Costa e Silva, buscou a afirmação dos direitos do homem - uma característica da evolução do Estado moderno. Segundo o presidente:

Para o chefe da Nação este é um momento muito especial de regozijo cívico, a instalação do Conselho de Defesa dos Direitos da Pessoa Humana não constitui um ato de rotina administrativa. Possui uma transcendência, no tempo e no espaço, que nos pode recordar o movimento progressivo da humanidade, conquistando e definido, ao preço de muita luta, de um esforço heroico das energias espirituais para romper o obscurantismo, a justiça e a amizade cívica de que falam os humanistas e filosóficos políticos, ao tratar das bases essenciais da comunidade das pessoas humanas (DIREITOS..., 1968, p. 2).

Ainda, como último ponto, a afirmação de compromissos enquanto "Chefe da Nação" junto ao Conselho: do governo, em estimular sempre o desenvolvimento das atividades educacionais; do Conselho como "templo onde a palavra não ficará morta, sem o calor das significações múltiplas de um verdadeiro humanismo" (DIREITOS..., 1968, p. 2); e claro, a defesa dos "Direitos do Homem". Por fim, ressalto a ideia, contida em seu discurso, de os direitos da pessoa humana como "luta constante do homem pela liberdade" e a procura de um ideal comum. Além disso, Costa e Silva traz o artigo 28 da Declaração Americana dos Direitos do Homem, “cuja essência do Governo procura fundir em seus atos e aspirações”, o qual coloca que "os direitos do homem estão limitados pelos direitos do próximo, pela segurança de todos e pelas justas exigências do bem-estar social e do desenvolvimento democrático" (DIREITOS..., 1968, p. 2).

O discurso do ministro da justiça Gama e Silva foi mais curto que o de Costa e Silva, mas tendo igual relevância. Ao iniciar a fala, exalta a instalação do CDDPH como "maior homenagem que o Brasil e o Governo de Vossa Excelência [Presidente Costa e Silva] podem prestar ao 'Ano Internacional dos Direitos Humanos"” (DIREITOS..., 1968, p. 2), quando se comemora, portanto, os 20 anos da Declaração Universal dos Direitos Humanos. Como o presidente Costa e Silva, o Ministro também ressalta os acordos e tratados internacionais, onde

esses instrumentos internacionais revelam, nos tempos modernos, uma profunda evolução do Direito Internacional, desde que a melhor doutrina se afastou dos conceitos clássicos para considerar ser o indivíduo, também, sujeito de Direito Internacional, rompendo liames que dificultam as relações entre os Estados (DIREITOS..., 1968, p. 2). 
Ainda, afirmando a instalação como ato de declaração do Estado de direito, da Constituição, das leis, da defesa da liberdade e da dignidade humana. Segundo o ministro:

É este ato uma resposta eloquente e afirmativa de que vivemos num Estado de Direito, sob o império da Constituição e das leis, onde o respeito à vida, à liberdade, à segurança e à propriedade são plenamente assegurados, sem prejuízo de outros direitos e garantias essenciais decorrentes do regime e dos princípios inscritos em nossa Lei Maior. E porque estamos num Estado de Direito, que tem na defesa da Constituição, das leis e da ordem uma de suas essenciais finalidades, é que o Poder Público age e atua, quando necessário, para manter a tranquilidade e o bem-estar de todos, ainda que muitas vezes sua energia, nem sempre honestamente compreendida, seja apontada como violadora daqueles direitos. E porque estamos num Estado de Direito é que este Conselho passa a ser o mais alto órgão fiscalizador da ação dos poderes públicos e dos particulares, promovendo e estimulando o respeito aos direitos do homem e às liberdades fundamentais e denunciando suas violações, em defesa dessas mesmas liberdades e da dignidade da pessoa humana. E porque estamos num Estado de Direitos é que repudiamos, mais uma vez, perante a augusta assembleia, a propalada existência entre nós de um Governo unipessoal e autocrático, caraterísticas que só poderiam qualificar um poder totalitário e jamais um Estado de Direito. E o Conselho de Defesa dos Direitos da Pessoa Humana, pela sua origem, por sua competência e composição é o mais positivo desmentido às intrigas e leviandades dos que pensam do modo diverso (DIREITOS..., 1968, p. 2).

Por diante, ressalta a fala do "eminente Clóvis Ramalhete" durante a Conferência Internacional das Organizações Não Governamentais sobre os Direitos Humanos, realizada em Paris, em setembro de 1968, onde recomendou a outros governos a criação de organismos que promovem inquéritos sobre fatores sociais e políticos de violação dos Direitos do Homem, assim "como já fez o Brasil”. Ao final, Gama e Silva afirma o Brasil como "exemplo de amor ao Direito, da crença na Liberdade, de fé no destino cristão da pessoa humana, de sua incoercível vocação pela ordem democrática, porque sem ela ou contra ela não há vida digna que valha a pena ser vivida" (DIREITOS..., 1968, p. 2).

Como havia destacado, ao ressaltar o Artigo 28 da Declaração Americana dos Direitos do Homem, Costa e Silva afirma como aspiração do Governo a segurança de todos pela justa exigência do bem-estar social e do desenvolvimento democrático - o que parece dentro do ideário dos articuladores da Revolução de 64, onde essa foi dada em nome da democracia, para salvá-la do perigo comunista. Isso também aparece na fala de Gama e Silva, quando define que o poder público age para manter a tranquilidade e bem-estar quando necessário, mas nem sempre é compreendido, assim, sendo apontado como violador dos Direitos do Homem. Ou seja, aqueles que definem o governo como violadores dessas garantias não compreendem que isso só foi necessário para um "bem maior".

Nos discursos encontramos a defesa da Constituição, essencialmente por Gama e Silva, além dos acordos internacionais, assim, entendendo como uma legitimação da instalação do 
Conselho. Além disso, a ideia da "Revolução de 64" como dentro de uma lógica mais ampla e histórica de trajetória da humanidade para o progresso, a liberdade e a democracia, ressaltada por Costa e Silva. Gama e Silva, em seu discurso, mobiliza constantemente a afirmação do Estado de direito no Brasil - pressuposto democrático dentro da lógica liberal, como forma de reafirmar os objetivos democráticos do governo (regime) ${ }^{13}$. Portanto, a defesa das garantias dos direitos do homem e de liberdades fundamentais seria por meio da instalação do Conselho, que representaria a efetiva afirmação do Estado de direito, ou seja, o limite do poder do Estado. Seria, por consequência, uma "resposta” àqueles que afirmam que o regime é um violador dos Direitos Humanos e das liberdades, ou ainda, que existe um governo unipessoal e autocrático. Dessa forma, a utilização da lógica liberal democrática para a legitimação do regime autoritário instalado em $1964^{14}$, bem como a sua diferenciação dos regimes totalitários.

\section{Direitos do homem e Estado de direito: limitação do Estado}

Norberto Bobbio, ao analisar os direitos naturais, define que eles representam o núcleo da doutrina liberal, sendo o preceito dos direitos do homem elaborado pela escola do direito natural, ou jusnaturalismo ${ }^{15}$, o pressuposto filosófico do Estado liberal como Estado limitado. Dessa forma, o liberalismo se constitui como concepção de Estado, onde ele tem poderes e funções limitadas, em contraposição aos Estados absolutos, às formas autocráticas como a monarquia ou oligarquia, além dos chamados Estados sociais. Destaca ainda duas exigências fundamentais de onde nasceram os Estados contemporâneos nos países socialmente e economicamente mais desenvolvidos: a exigência de limitar o poder de um lado e de outro distribuí-lo. Segundo Bobbio, a doutrina dos direitos do homem define que

todos os homens, indiscriminadamente, têm a natureza e, portanto, independentemente de sua própria vontade, e menos ainda da vontade de alguns poucos ou de apenas um, certos direitos fundamentais, como o direito à vida, à liberdade, à segurança, à felicidade - direitos esses que o Estado, ou mais corretamente aqueles que num determinado momento histórico detêm o poder legítimo de exercer a foça para obter a obediência a seus comandos devem

\footnotetext{
${ }_{13}$ Destaco aqui o preâmbulo do Ato Institucional n. ${ }^{\circ}$ 5, promulgado em 13 de dezembro de 1968, poucos dias depois da instalação do $\mathrm{CDDPH}$, que também definia os objetivos democráticos, compromisso com a liberdade e com respeito à dignidade humana da "Revolução de 64".

${ }_{14}$ A partir da tradição do pensamento autoritário brasileiro, podemos ponderar que muitos teóricos buscaram sempre pensar e propor relações entre o autoritarismo no Brasil e o liberalismo. Assim, como o cientista político Wanderley Guilherme dos Santos propõe uma divisão das famílias intelectuais em duas: liberais doutrinários e autoritários instrumentais. Dessa forma, a partir de uma interpretação de Oliveira Vianna, destaca a instrumentalização de recurso autoritário, como transitório pelo atraso da realidade, que buscaria um futuro liberal - por isso, autoritarismo instrumental (HOLANDA; COSER, 2016). Tal interpretação foi abordada por Cristina Buarque de Holanda e Ivo Coser no artigo "Realismos Autoritário e Liberal: Aspectos da Imaginação sobre Representação Política em Fins de Século XIX e Princípios do XX”, que buscou fazer um levantamento e discussão do pensamento autoritário brasileiro e sua relação com as teorias liberais (2016). Além disso, Maria Stella Martins Bresciani, em seu livro "O charme da ciência e a sedução da objetividade", também propõe uma interpretação do pensamento autoritário de Oliveira Vianna e a relação com o liberalismo (2005).

15 Entendida por Norberto Bobbio como a "doutrina segundo a qual existem leis não postas pela vontade humana" (BOBBIO, 1992, p. 12). Além de destacar como pressuposto filosófico que serve para fundar os limites do poder.
} 
respeitar, e portanto não invadir, e ao mesmo tempo proteger contra toda possível invasão por parte dos outros (BOBBIO, 1992, p. 11)

Dessa forma, a doutrina de direitos naturais está na base, tanto da Declaração dos Direitos, proclamada nos Estados Unidos da América (1776), quanto na da França revolucionária (1789), afirmando o princípio do Estado liberal como Estado limitado. Essas limitações se caracterizam no âmbito de poder na noção de "Estado de direito" e no âmbito das funções o "Estado mínimo" - as duas noções, ressalta o autor, não possuem dependência, ou seja, pode ocorrer Estado mínimo sem Estado de direito e vice-versa. Dessa maneira, o Estado de direito se contrapõem ao Estado absoluto e o Estado mínimo ao máximo.

Por Estado de direito entende-se geralmente um Estado em que os poderes públicos são regulados por normas gerais (as leis fundamentais ou constitucionais) e devem ser exercidos no âmbito das leis que os regulam, salvo o direito do cidadão de recorrer a um juiz independente para fazer com que seja reconhecido e refutado o abuso ou excesso de poder. [...] Por outro lado, quando se fala de Estado de direito no âmbito da doutrina liberal do Estado, deve-se acrescentar à definição tradicional uma determinação ulterior: a constitucionalização dos direitos naturais, ou seja, a transformação desses direitos em direitos juridicamente protegidos, isto é, em verdadeiros direitos positivos. $\mathrm{Na}$ doutrina liberal, Estado de direito significa não só a subordinação dos poderes públicos de qualquer grau às leis gerais de um país, limite que é puramente formal, mas também a subordinação das leis ao limite material do reconhecimento de alguns direitos fundamentais considerados constitucionalmente e, portanto, em linha de princípios “invioláveis" (BOBBIO, 2000, p. 18-19).

Segundo Bobbio, pode-se ter dois pontos de vista sobre o Estado de direito, no sentido forte e fraco: o Estado de direito no sentido fraco é o Estado não despótico, que é dirigido não pelos homens, mas pelas leis; no sentido forte, que é o da doutrina liberal, "são parte integrante todos os mecanismos constitucionais que impedem ou obstaculizam o exercício arbitrário e ilegítimo do poder e impedem ou desencorajam o abuso ou o exercício ilegal do poder" (BOBBIO, 2000, p. 19). Para ele, existem quatro mecanismos mais importantes nesse de caráter forte: o controle do Poder Executivo por parte do Legislativo; controle eventual do parlamento no exercício de "Poder Legislativo ordinário", como parte de uma corte jurisdicional que verifica a constitucionalidade das leis; relativa autonomia dos governos locais, com respeito ao governo central; e uma magistratura independente do poder político. Dessas 
formas, esses mecanismos constitucionais têm o objetivo de defender o indivíduo dos abusos de poder e garantir a liberdade ${ }^{16}$ - O Estado de direito é o Estado dos cidadãos ${ }^{17}$.

Das premissas do Estado liberal se destaca a igualdade, segundo Bobbio, inspirada em dois princípios fundamentais, anunciados em formas constitucionais: igualdade perante a lei; igualdade dos direitos - tais princípios que atravessam toda a história constitucionalista. Isso significa dizer que todos os cidadãos devem ser submetidos sob a mesma lei e esse "princípio é igualitário porque elimina uma discriminação precedente” (BOBBIO, 2000, p. 40), assim, também significa de igual gozo dos cidadãos os direitos fundamentais constitucionalmente invioláveis.

Além disso, pensando esta estruturação e construção do Estado liberal, pode se ter como resultado de seu aperfeiçoamento a democracia. Dessa forma, ela pode ser considerada tanto natural do Estado liberal pela sua fórmula política que é a soberania popular, além do ideal igualitário.

Deve-se dizer que se foi formada uma tal interdependência entre um e outro, que enquanto no início puderam se formar Estados liberais que não eram democráticos (a não ser nas declarações de princípios), hoje Estados liberais não democráticos não seriam mais concebíveis, nem Estados democráticos que não fossem também liberais. Existem em suma, boas razões para crer: a) que hoje o método democrático seja necessário para a salvaguarda dos direitos fundamentais da pessoa, que estão na base do Estado liberal; b) que a salvaguarda desses direitos seja necessária para correto funcionamento do método democrático (BOBBIO, 2000, p. 43).

Para Bobbio, os direitos do homem são direitos históricos, nascidos em certas circunstâncias e caraterizados pelas lutas em defesa das liberdades contra os velhos poderes, além de nascer de forma gradual, por mais fundamentais que sejam. Além disso, esses direitos se modificam constantemente, com mudança das condições históricas, "ou seja, dos carecimentos e dos interesses, das classes no poder, dos meios disponíveis para a realização dos mesmos, das transformações técnicas etc.” (BOBBIO, 1992, p. 18).

Estado de Direito e os direitos e garantias fundamentais tornaram-se premissas fundamentais dos Estados contemporâneos, difundindo-se nas constituições democráticas - pelo menos nas suas construções teóricas. Além disso, de fato, passada a Segunda Guerra Mundial, os Direitos Humanos ganham um olhar mais humanista e universalizam no sentido global, passando do nacional para o internacional. Nesse sentido, nasceu a Declaração Universal dos Direitos Humanos, em 10 de dezembro de 1948, em uma discussão levantada pela Organização

\footnotetext{
${ }^{16}$ Concepção de liberdade na tradição liberal, onde "liberdade" e "poder" são termos opostos e contrastantes. Dessa forma, na doutrina liberal a liberdade definida como "liberdade em relação ao Estado" e o Estado liberal se constitui como alargamento da esfera de liberdade do indivíduo diante dos poderes públicos (BOBBIO, 2000, p. 22). Além disso, "a diferença entre liberalismo e autoritarismo (melhor que totalitarismo) está na diversa conotação positiva ou negativa dos dois termos opostos, poder e liberdade, e das consequências que disso derivam. O liberalismo é a doutrina na qual a conotação positiva cabe ao termo "liberdade", com a consequência de que uma sociedade é tanto melhor quanto mais extensa é a esfera da liberdade e restrita do poder" (BOBBIO, 2000, p. 89).

${ }_{17}$ O jurista Manoel Gonçalves Ferreira Filho, seguindo essa linha, define que o Estado de Direito, "em sua fórmula típica e original, caracteriza-se, primeiro pelo reconhecimento de que o Poder é limitado por um Direito superior, que está fora de seu alcance mudar. Tal direito, natural porque inerente à natureza do homem, constitui a fronteira que sua atuação legítima não pode ultrapassar" (FERREIRA FILHO, 1999, p. 5).
} 
das Nações Unidas (ONU). Os direitos, que antes estavam dispostos a variações, interpretações e momentos históricos de cada Estado, passaram a ser entendidos de caráter globalizante nenhum Estado, grupo ou pessoa tem o direito de exercer práticas ou atividades que destruam os direitos e liberdades estabelecidos na Declaração. Tais direitos são, entre outros: liberdade, à vida, segurança pessoal, liberdade de expressão e opinião, proteção, pleno direito à lei e julgamento imparcial, etc. Os Direitos Humanos, a partir desse momento, são compreendidos como modelo ético das sociedades contemporâneas, um paradigma referencial.

A historiadora Lynn Hunt (2009), na obra A invenção dos Direitos Humanos, propõe a construção histórica dos Direitos Humanos e destaca que a Declaração Universal dos Direitos Humanos "cristalizou” 150 anos de luta pelos direitos. Desta forma, afirma que:

A Declaração Universal dos Direitos Humanos não afirmava simplesmente as noções de direitos individuais do século XVIII, tais como a igualdade perante a lei, a liberdade de expressão, a liberdade de religião, o direito de participar do governo, a proteção da propriedade privada e a rejeição da tortura e da punição cruel. Ela também proibia expressamente a escravidão e providenciava o sufrágio universal e igual por votação secreta. Além disso, requeria a liberdade de ir e vir, o direito a uma nacionalidade, o direito de casar e, com mais controvérsia, o direito à segurança social; o direito de trabalhar, com pagamento igual, tendo por base um salário de substância; o direito de descanso e ao lazer; e o direito à educação, que devia ser grátis nos níveis elementares (HUNT, 2009, p. 206).

Portanto, a Declaração Universal buscou incorporar diversas reinvindicações históricas e construir preceitos morais internacionais, como o exemplo colocado por Hunt: a luta abolicionista levantada pelos americanos e britânicos desde o século XIX; a liberdade de expressão, ligada à liberdade de imprensa; a igualdade de gênero, motivado pela luta de sufrágio universal; etc. Da mesma forma que os Direitos Humanos foram uma construção histórica, após 1948 incorporou diversas lutas e reinvindicações sociais, questões como: ampliação da noção de acesso à educação e saberes, saneamento, lazer, cultura etc. Para a autora, "a Declaração Universal é mais o início do processo do que seu apogeu” (HUNT, 2009, p. 209) e, assim, se colocou uma discussão mundial e um processo de institucionalização - com a criação de cortes e entidades internacionais.

\section{Considerações finais}

A abertura do Conselho de Defesa dos Direitos da Pessoa Humana pela ditadura civil-militar, durante o governo Costa e Silva, não assegurou os Direitos Humanos, o Estado de direito, as garantias fundamentais, as leis e a Constituição no Brasil. O mesmo regime que, por meio de seus representantes - o presidente Costa e Silva e o ministro Gama e Silva - proferiram discursos sobre essas garantias jurídicas, promulgou o Ato Institucional n. ${ }^{\circ} 5$ em dezembro de 1968. A partir disso, qualquer garantia jurídica ficou suspensa e o presidente passou a ter poderes de 
intervir em qualquer esfera para a garantia da ordem e, supostamente, da democracia - inclusive sobre o poder Legislativo, o Congresso Nacional, e as esferas políticas estaduais. Portanto, mesmo com a tentativa de caracterização das arbitrariedades enquanto dentro da lei, a efetiva garantia da constituição e do Estado de direito não era uma premissa da ditadura civil-militar.

Além disso, os direitos e garantias naturais e invioláveis também não eram uma limitação para a atuação do regime militar. Durante os 21 anos da ditadura, esses direitos e a liberdade foram constantemente violados pelo aparato repressivo institucional do Estado. O Conselho de Defesa dos Direitos da Pessoa Humana, que seria o órgão fiscalizador de as todas violações dos Direitos Humanos, dos agentes públicos e privados, nunca teve autonomia para a investigação de qualquer denúncia que chegava até os conselheiros. Dessa forma, a proferida atuação do Conselho nunca chegou a ter espaço e o avanço que sua abertura profetizava, acabou ficando amarrado até o processo de redemocratização do país.

Assim sendo, o Estado de Direito proferido pelo Ministro Gama e Silva e constantemente buscado em seu discurso para caracterizar a ditadura não representava uma realidade brasileira. Esse conceito, relativo ao Estado liberal, necessita de uma efetiva democracia e, principalmente, a limitação do Estado com o respeito e as garantias de direitos fundamentais, invioláveis e para todos - os Direitos Humanos. Ressalto aqui que não se trata de um tribunal sobre o presidente Costa e Silva e o ministro Gama e Silva entre discurso e prática, o historiador não é um juiz, mas procuro salientar a busca de caracterização da ditadura civil-militar quanto democrática e constitucional. Essa é uma característica essencial da ditadura brasileira: manter uma aparência democrática e uma normalização institucional e constitucional - os Atos Institucionais, a manutenção do sistema judiciário e legislativo (mesmo de forma controlada, às vezes mais e às vezes menos) e constante aprovação de leis e a Constituição.

\section{Referências}

BAUER, Caroline Silveira. Avenida João Pessoa, 2050 - $3^{\mathbf{o}}$ Andar: Terrorismo de Estado e Ação da Polícia Política do Departamento de Ordem Política e Social do Rio Grande do Sul (1964-1982). 2006. Dissertação (Mestrado em História)-Universidade Federal do Rio Grande do Sul, Porto Alegre, 2006.

BELOCH, Israel; LATTMAN-WELTMAN, Fernando; LAMARÃO, Sérgio Tadeu de Niemayer. Dicionário Histórico-Biográfico Brasileiro: pós-1930. 2. ed. rev. e atual. Rio de Janeiro: FGV/ CPDOC, 2001.

BOBBIO, Norberto. Liberalismo e democracia. Tradução: Marco Aurélio Nogueira. São Paulo: Brasiliense, 2000.

BOBBIO, Norberto. A era dos direitos. Tradução: Carlos Nelson Coutinho. Rio de Janeiro: Campus, 1992.

BRASIL. Lei no 4.319, de 16 de março de 1964. Cria o Conselho de Defesa dos Direitos da Pessoa Humana. Brasília, DF, 1964. Disponível em: http://www.planalto.gov.br/ccivil_03/ LEIS/1950-1969/L4319.htm. Acesso em: 10 set. 2018.

BRASIL. Congresso Nacional. Projeto de Lei 1221, de 25 de abril de 1956. Cria o Conselho de Defesa dos Direitos da Pessoa Humana. Diário do Congresso Nacional: Poder Legislativo, 
Brasília, Seção I, Ano XI, n. 66, 26 abr. 1956. Disponível em: http://imagem.camara.gov.br/ Imagem/d/pdf/DCD26ABR1956.pdf\#page=10. Acesso em: 10 set. 2018.

BRASIL. Projeto de Lei aprovado e transformado na Lei 5.763 de 15 de dezembro de 1971. Congresso Nacional, 1971. Disponível em: http://www.planalto.gov.br/ccivil_03/leis/19701979/L5763.htm\#art1. Acesso em: 10 set. 2018.

BRESCIANI, Maria Stella Martins. O charme da ciência e a sedução da objetividade: Oliveira Vianna entre intérpretes do Brasil. São Paulo: Editora UNESP, 2005.

DIREITOS: conselho instalado. Correio da Manhã, Rio de Janeiro, 25 out. 1968. I Caderno, p. 02. FERREIRA FILHO, Manuel Gonçalves. Estado de direito e constituição - e ed. rev. ampl. São Paulo: Saraiva, 1999.

FICO, Carlos. História do Brasil contemporâneo. São Paulo: Contexto, 2016.

HOLANDA, Cristina Buarque de; COSER, Ivo. Realismos Autoritário e Liberal: Aspectos da Imaginação sobre Representação Política em Fins do Século XIX e Princípios do XX. Revista de Ciências Sociais, Rio de Janeiro, v. 59, n. 3, p. 903-946, 2016. https://doi. org/10.1590/00115258201695

HUNT, Lynn. A invenção dos direitos humanos: uma história. São Paulo: Companhia das Letras, 2009.

MENDES, Ricardo Antonio Souza. Ditaduras civil-militares no Cone Sul e a Doutrina de Segurança Nacional - algumas considerações sobre a Historiografia. Revista Tempo e Argumento, Florianópolis, v. 5, n.10, a. 13. p. 6-38.

NAPOLITANO, Marcos. 1964: história do regime militar brasileiro. 1. ed., 4. reimpr. São Paulo: Contexto, 2017.

NAPOLITANO, Marcos. Recordar é vencer: as dinâmicas e vicissitudes da construção da memória sobre o regime militar brasileiro. Antíteses, Londrina, v. 8, n. 15, esp., p. 9-44, nov. 2015.

PADRÓS, Enrique. América Latina: Ditadura, Segurança Nacional e Terror de Estado. História e Luta de Classes: América Latina Contemporânea, [S. 1.], n. 4, p. 43-49, 2007.

PADRÓS, Enrique. Como el Uruguay no hay...: terror de Estado e segurança nacional Uruguai (1968-1985): do pachecato à ditadura civil-militar. Tese em História. Programa de Pós-graduação em História, UFGRS, Porto Alegre, 2005.

REIS, Daniel Aarão. Ditadura militar, esquerdas e sociedade. Rio de Janeiro: Jorge Zahar Ed., 2000.

RIDENTI, Marcelo. As oposições à ditadura: resistência e integração. In: REIS FILHO, Daniel Aarão; RIDENTI, Marcelo; MOTTA, Rodrigo Patto Sá (org.). A ditadura que mudou o Brasil: 50 anos do golpe de 1964. Rio de Janeiro: Zahar, 2014, p. 30-47.

SILVA, Leonardo Fetter da. A ditadura civil-militar e os Direitos Humanos: o Conselho de Defesa dos Direitos da Pessoa Humana. In: CONGRESSO INTERNACIONAL DE ESTUDOS IBERO-AMERICANOS (CIEIA), 11, out. 2017, Porto Alegre. Anais do [...]. Disponível em: http://ebooks.pucrs.br/edipucrs/acessolivre/anais/cieia/assets/edicoes/2017/arquivos/4.pdf. Acesso em: 22 ago. 2018.

Recebido em: 23/9/2018.

Aprovado em: 8/1/2019. 